\title{
Analisis Kelayakan Produksi Silikon dari Abu Ampas Tebu
}

\section{Feasibility Analysis Production Silicon from Bagasse Ashes}

Bambang Mulyana Hermanto ${ }^{\mathrm{a}}$, Erliza Noor ${ }^{\mathrm{b}}$, Yandra Arkeman ${ }^{\mathrm{b}}$, Etty Rianic

${ }^{a}$ Program Studi Ilmu Pengelolan Sumberdaya Alam dan Lingkungan, Sekolah Pascasarjana, Institut Pertanian Bogor, Kampus IPB Baranangsiang, Bogor 16144

${ }^{\mathrm{b}}$ Departemen Teknologi Industri Pertanian, Fakultas Teknologi Pertanian, Institut Pertanian Bogor, Kampus IPB Dramaga, Bogor 16680

${ }^{\mathrm{c}}$ Departemen Manajemen Sumberdaya Perairan Fakultas Perikanan dan Ilmu Kelautan Institut Pertanian Bogor, Kampus IPB Dramaga, Bogor 16680

\section{Article Info:}

Received: 26 - 05 - 2017

Accepted: 02 - $10-2018$

\section{Keywords:}

Bagasse Ashes, Feasibility

Production, Silicon.

Corresponding Author: Bambang Mulyana Hermanto Program Studi Ilmu Pengelolaan Sumberdaya Alam dan Lingkungan, Institut Pertanian Bogor; Email: bambang_mulyana15@yahoo.co $\mathrm{m}$

\begin{abstract}
It is estimated that the increase of sugarcane production will also increase the amount of bagasse. Sugar mills utilize dried bagasse as boiler fuel and the burning results a bagasse ash.Unrefined bagasse is estimated to contribute to the impact of the environment, including health problems when inhaled by humans. When covers the leaves, it will block the process of photosynthesis in plant. This are due to the size of ash and the contents of silica dioxide compound inside the bagasse. Besides providing impact, silica dioxide compounds are compounds that have high economic value as it can be used as silicon. The purposes of the utilization of bagasse ashes into silicon are to reduce the impact on the environment, to increase the economic value of bagasse ash and to empower community. The results of the feasibility analysis of silicon production from bagasse ash arethe planned production capacity of 10,000 tons/year, breakeven point (BEP) that is 3,400 tons/year or $34 \%$ of production capacity, Return of Investment (ROI) that is $28 \%$, Payout Time (POT) of 3,6 years and 28,25\% of Internal Rate of Return (IRR).Therefore, the plan to utilize the bagasse ash from silicon can be considered to be done.
\end{abstract}

How to cite (CSE Style $8^{\text {th }}$ Edition):

Hermanto BM, Noor E, Arkeman Y, Riani E. 2019. Feasibility analysis production silicon from bagasse ashes. JPSL 9(3): 818-825. http://dx.doi.org/10.29244/jpsi.9.3.818-825.

\section{PENDAHULUAN}

Ampas tebu yang telah kering digunakan untuk energi pembakaran ketel uap di pabrik gula. Abu ampas tebu akan mengalami peningkatan seiring dari peningkatan kapasitas produksi gula tebu.

Hasil penelitian (Teixeira et al. 2009) abu ampas tebu mengandung senyawa silika dioksida $\left(\mathrm{SiO}_{2}\right)$ sebesar $89,61 \%$ dan 50,36 \% (Afandi et al. 2009). Senyawa silika dioksida $\left(\mathrm{SiO}_{2}\right)$ merupakan bahan dasar pembuatan silika (Kalapathy et al. 2002), (Worathanakul et al. 2009), silikon karbida (Suparman 2010), semikonduktor (Rohaeti et al. 2010). Silika dioksida $\left(\mathrm{SiO}_{2}\right)$ untuk produksi silikon, selama ini bersumber dari hasil ekstraksi mineral alam pasir atau batuan yang mengandung senyawa silika dioksida $\left(\mathrm{SiO}_{2}\right)$. Sumber silika dioksida yang berasal dari alam digolongkan sebagai material yang tidak dapat diperbaharui dan apabila terus dilakukan eksploitasi, berdampak pada ketersedian di alam yang semakin menipis. 
Potensi ampas tebu sebagi sumber abu ampas tebu di Indonesia berdasarkan data dari Pusat Penelitian Perkebunan Gula Indonesia (P3GI) sebesar 32\% dari berat tebu giling atau sekitar 10200000 ton/tahun permusim. Baggase yang telah dimanfaatkan sebesar 60\% atau 6120000 ton/tahun sebagai bahan bakar ketel uap pabrik gula, bahan baku industri kanvas rem, industri jamur dan lain-lain, sisa baggase yang belum dimanfaatkan sebesar 40\% atau 4080000 ton/tahun (Husin 2007). Pemanfaatan abu ampas tebu menjadi silikon merupakan salah satu upaya untuk mengurangi eksploitasi mineral alam pasir dan batuan yang mengandung silika dioksida .

Abu ampas tebu memberikan dampak terhadap manusia dan tanaman. Hal ini dikarenakan ukuran partikel abu ampas tebu berkisar 1-10 mikron. Ukuran tersebut dapat menyebabkan penyakit Pneumokoniosis pada manusia. Dampak abu ampas tebu selain pada manusia juga dapat memberikan dampak terhadap tumbuhan. Abu ampas tebu yang bercampur dengan uap air atau air hujan gerimis, dapat menyebabkan kerak tebal pada permukaan daun. Kerak yang terbentuk tidak dapat dihilangkan dengan air hujan, namun dapat dihilangkan dengan cara digosok dengan air. Daun yang tertutup oleh kerak dapat menghambat proses fotosintesis dan pertukaran $\mathrm{CO}_{2}$ dengan atmosfer (Fardiaz 1992).

Abu ampas tebu yang memiliki kandungan silika dioksida yang tinggi dapat dimanfaatkan menjadi silikon. Bahan baku silikon banyak digunakan dalam bidang elektronika, peralatan dan perabotan rumah tangga, industri kimia dan otomotif. Dengan pemanfaatan silikon dari abu ampas tebu diperkirakan dapat mengurangi penggunaan silikon yang bersumber dari alam yang tidak dapat diperbaharui dan mengurangi dampak terhadap lingkungan. Dengan adanya dampak dan potensi abu ampas tebu menjadi silikon, diperlukan analisis kelayakan produksi silikon dari abu ampas tebu.

Abu ampas tebu hingga saat ini masih belum termanfaatkan secara optimal, padahal abu ampas tebu dapat dimanfaatkan menjadi silikon. Di lain pihak Indonesia masih mengimpor silikon dan permintaanya cenderung mengalami peningkatan setiap tahun. Upaya pemanfaatan abu ampas tebu menjadi silikon merupakan salah satu potensi yang memiliki nilai tambah tinggi. Upaya pemanfaatan abu ampas tebu perlu dikaji dari berbagai aspek. Terkait hal tersebut muncul pertayaan penelitian , bagaimana analisis terkait kelayakan produksi silikon dari abu ampas tebu.

Tujuan umum penelitian ini adalah untuk pemanfaatan abu ampas tebu menjadi silikon, adapun tujuan khusus penelitianya adalah melakukan analisis kelayakan produksi silikon dari abu ampas tebu

\section{METODE}

\section{Waktu dan Tempat}

Penelitian ini dilakukan dari bulan Desember 2015 sampai Juli 2016 bertempat di Pabrik Gula Jati Tujuh Kabupaten Majalengka Provinsi Jawa Barat serta Kampus IPB Dramaga dan Baranangsiang.

\section{Bahan dan Alat}

Bahan penelitian berupa data primer dan data sekunder. Data primer didapatkan dari hasil wawancara langsung dengan pihak terkait antara lain praktisi, akademisi dan birokrat. Data sekunder diperoleh dari studi pustaka dalam rangka memperoleh landasan teoritis dan data penunjang yang berkaitan dengan materi penelitian, berupa buku referensi, laporan hasil penelitian, jurnal, artikel ilmiah dan tulisan ilmiah lainnya. Peralatan yang digunakan adalah seperangkat komputer Microsoft Office dan kamera digital. 


\section{Analisis data}

Bahan penelitian berupa data primer dan data sekunder. Data primer didapatkan dari hasil wawancara langsung dengan pihak terkait antara lain praktisi, akademisi dan birokrat. Data sekunder diperoleh dari studi pustaka dalam rangka memperoleh landasan teoritis dan data penunjang yang berkaitan dengan materi penelitian, berupa buku referensi, laporan hasil penelitian, jurnal, artikel ilmiah dan tulisan ilmiah lainnya. Peralatan yang digunakan adalah seperangkat komputer Microsoft Office dan kamera digital

Tahap pertama proses produksi silikon dari abu ampas tebu adalah proses pencucian. Tujuan dari proses pencucian ini adalah untuk dipisahkan antara abu ampas tebu terhadap kotoran yang masih terbawa. Tahap kedua setelah proses pencucian adalah proses proses pengeringan. Abu ampas tebu setelah kering dilakukan proses pemisahan, tujuan dari proses pemisahan ini adalah untuk menghilangkan senyawa - senyawa organik lain yang masih ada. Proses berikutnya adalah pemanasan, proses ini dilakukan untuk menghilangkan senyawa- senyawa lain, setelah dilakukan penambahan senyawa kimia dan memurnikan produk pada suhu 750 ${ }^{\circ} \mathrm{c}$. Produk yang keluar dari tahap ini masih dalam keadaan panas, untuk itu perlu dilakukan proses pendinginan sebelum dilanjutkan proses pemurnian.

Proses pemurnian yang ke dua, tujuan dari proses pemurnian tahap dua adalah untuk menghilangkan senyawa kimia lain dan produk dimurnikan dengan cara dipanaskan pada suhu $650{ }^{\circ} \mathrm{c}$. Produk yang keluar masih dalam keadaan panas, sebelum dilanjutkan terlebih dahulu dilakukan proses pendinginan. Produk yang sudah dingin dilanjutkan dengan proses penyaringan, tujuan dari proses ini adalah untuk memisahkan antara produk dengan senyawa lain yang masih ada. Tahap akhir dari proses ini adalah proses pengeringan pengeringan, tujuannya adalah untuk menghilangkan senyawa lain yang masih terbawa pada produk. Produk yang keluar dari proses ini merupakan produk jadi berupa silikon. Adapun bagan alir dari rencana proses produksi silikon dapat dilihat pada Gambar 3 dan peralatan yang digunakan terdapat pada Tabel 1.

\section{Penetapan kapasitas produksi}

Penetapan kapasitas produksi silikon dari abu ampas tebu didasarkan atas kebutuhan dalam negeri yang selama ini masih impor dan kebutuhan silikon dunia yang diperkirakan akan terus bertambah (BPS 2014). Adapun perkiraan kebutuhan silikon dalam negeri di tahun 2017 sebesar 409330.9 kg/tahun, hal ini berdasarkan hasil perhitungan dari persamaan $\mathrm{y}=45991 \mathrm{x}-4588.1$ dan data kebutuhan silikon dunia di tahun 2011 sebesar $8000000 \mathrm{~kg} / \mathrm{tahun}$.

\section{Perhitungan titik impas}

Titik impas (BEP) adalah keadaan kapasitas produksi pabrik pada saat hasil penjualan hanya dapat menutupi biaya produksi. Dalam keadaan ini pabrik tidak untung dan tidak rugi. Besarnya titik impas yang umum untuk suatu pabrik adalah 30\% - 85\% (Colin Drury, 2004). penjualan Rp. 255000000 pada saat produksi mencapai $30 \%$.

\section{Laju pengembalian modal}

Laju pengembalian modal adalah besarnya persentase pengembalian modal tiap tahun dari penghasilan bersih. Dari hasil perhitungan ini berdasarkan ROI $\leq 15 \%$ resiko pengembalian modal rendah, $15 \% \leq \mathrm{ROI} \leq$ $45 \%$ resiko pengembalian modal rata-rata, $\mathrm{ROI} \geq 45 \%$ resiko pengembalian modal tinggi

\section{Laju pengembalian modal internal}

Laju pengembalian modal internal (IRR) merupakan persentase yang menggambarkan keuntungan ratarata bunga pertahunnya dari semua pengeluaran dan pemasukan besarnya sama. Apabila IRR ternyata lebih besar dari bunga riil yang berlaku, maka pabrik akan menguntungkan tetapi bila IRR lebih kecil dari bunga 
riil yang berlaku maka pabrik dianggap rugi. Kategori resiko pengembalian modal tersebut antara lain $\mathrm{ROI} \leq$ $15 \%$ resiko pengembalian modal rendah, $15 \% \leq \mathrm{ROI} \leq 45 \%$ resiko pengembalian modal rata-rata, $\mathrm{ROI} \geq 45 \%$ resiko pengembalian modal tinggi (Timmerhaus et al. 2004).

\section{HASIL DAN PEMBAHASAN}

\section{Penetapan kapasitas produksi}

Berdasarkan hasil analisis penetapan kapsitas produksi silikon dari abu ampas tebu sebesar 10000 ton/tahun. Untuk mengetahui penentuan kapasitas produksi dapat dilihat pada Gambar 1.

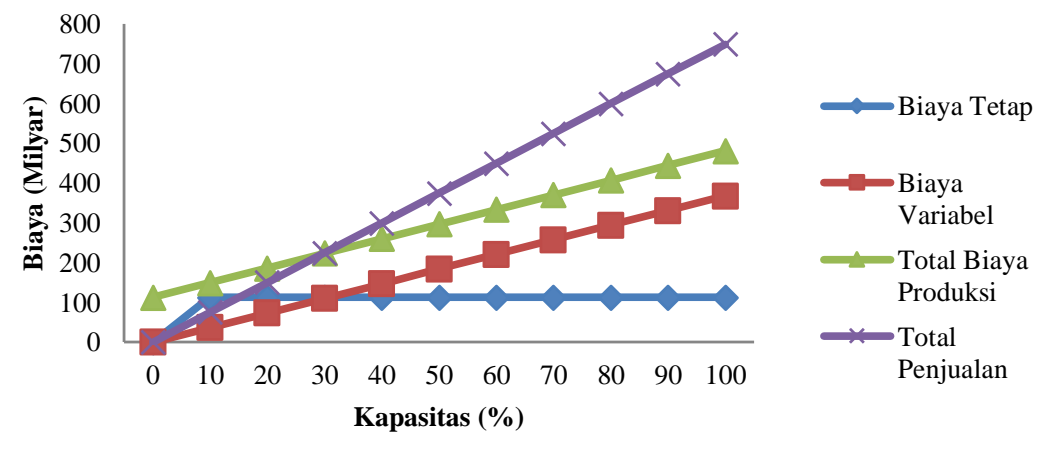

Gambar 1 Kapasitas produksi.

Penetapan kapasitas produksi silikon dari abu ampas tebu didasarkan atas kebutuhan dalam negeri yang selama ini masih impor dan kebutuhan silikon dunia yang diperkirakan akan terus bertambah. Adapun perkiraan kebutuhan silikon dalam negeri ditahun 2017 sebesar $409330.9 \mathrm{~kg} / \mathrm{tahun}$. Hal ini berdasarkan hasil perhitungan dari persamaan $\mathrm{y}=45991 \mathrm{x}-4588.1$ yang tertera pada Gambar 1 dan data kebutuhan silikon dunia pada tahun 2011 sebesar $8000000 \mathrm{~kg} /$ tahun. Berdasarkan analisis tersebut penetapan kapasitas produksi silikon dari baggase sebesar 10000 ton/tahun.

\section{Perhitungan titik impas}

Sesuai hasil perhitungan titik impas untuk produksi silikon dari abu ampas tebu sebesar $34 \%$, nilai tersebut diantara 30\% - 85\% dengan nilai penjualan Rp. 255000000 pada saat produksi mencapai 30\% terdapat pada Gambar 2.

Gambar 2 menunjukan bahwa rencana kapasitas 10000 ton/tahun diperoleh nilai titik impas $(B E P)$ pada saat produksi mencapai 3400 ton/tahun atau produksi berjalan pada kapasitas produksi mencapai 34\%, dengan nilai penjualan sebesar Rp. 255000000000 dari kapasitas 10000 ton/tahun atau 100\% dengan investasi total sebesar Rp 871471 287,028 pabrik silikon pada kapasitas 3,400 ton tidak mengalami kerugian dan belum mendapatkan keuntungan, hasil produksi yang terjual baru dapat mengembalikan modal. Nilai titik impas yang umum untuk suatu pabrik berada diantara range 30\%-85\% (Drury, 2004). Pabrik silikon dari baggase memiliki nilai titik impas $34 \%$, masuk dalam range $30 \%-85 \%$.

\section{Laju pengembalian modal}

Kelayakan produksi silikon dari abu ampas tebu dapat dilihat dari nilai laju pengembalian modal (ROI). Nilai dari $R O I$ industri silikon dari baggase setelah pajak adalah sebesar $28 \%$. Apabila nilai $R O I \leq 15 \%$ resiko pengembalian modal rendah, nilai $15 \% \leq R O I \leq 45 \%$ resiko pengembalian modal rata-rata, $R O I \geq 45 \%$ resiko pengembalian modal tinggi. Dari nilai $R O I 28 \%$ maka indsutri silikon dari abu ampas tebu memiliki resiko pengembalian keuntungan atas investasi atau modal rata-rata, dikarenakan berada diantara nilai range antara $15 \% \leq R O I \leq 45 \%$ (Timmerhaus et al. 2004). 


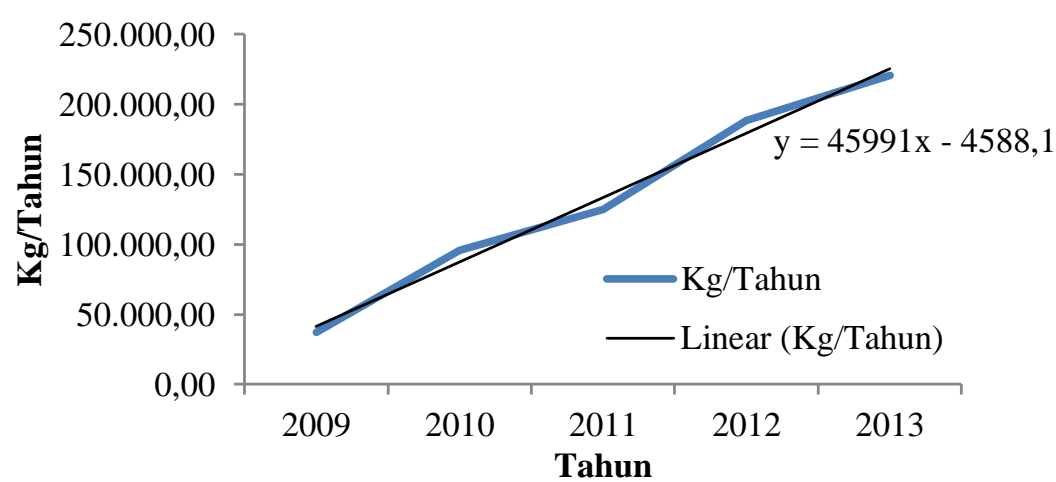

Gambar 2. Penentuan titik impas (BEP)

\section{Waktu pengembalian modal}

Waktu pengembalian modal adalah angka yang menunjukkan berapa lama waktu pengembalian modal dengan membandingkan besar total modal investasi dengan penghasilan bersih setiap tahun. Untuk itu, pabrik dianggap beroperasi pada kapasitas penuh setiap tahun, dari hasil analisis dapat dilihat bahwa seluruh modal investasi akan kembali setelah 3.6 tahun operasi. Nilai POT menunjukan lamanya pabrik silikon dari abu ampas tebu dapat mengembalikan modal dimulai sejak pabrik beroperasi, dengan demikian seluruh modal investasi akan kembali setelah 3.6 tahun operasi

\section{Laju pengembalian modal internal}

Hasil analisis laju pengembalian modal internal (IRR) merupakan persentase yang menggambarkan keuntungan rata-rata bunga pertahun dari semua pengeluaran dan pemasukan sama besar dari pabrik silikon dari abu ampas tebu. Apabila IRR lebih besar dari bunga riil yang berlaku, maka pabrik akan menguntungkan, tetapi bila IRR lebih kecil dari bunga riil yang berlaku maka pabrik dianggap rugi. Kategori resiko pengembalian modal tersebut antara lain ROI $\leq 15 \%$ resiko pengembalian modal rendah, $15 \% \leq$ ROI $\leq 45 \%$ resiko pengembalian modal rata-rata, $\mathrm{ROI} \geq 45 \%$ resiko pengembalian modal tinggi. Berdasarkan hasil analisis didapatkan nilai IRR sebesar $28.25 \%$, sehingga pabrik silikon akan menguntungkan karena, IRR yang diperoleh lebih besar dari bunga pinjaman bank saat ini, sebesar 22\% (Bank BRI 2015). Pemanfaatan abu ampas tebu menjadi silikon memberikan nilai tambah dalam upaya mendukung pembangunan berkelanjutan. Ketersedian dan harga abu ampas tebu memegang peranan sangat penting dalam keberlanjutan produksi silikon. Silikon banyak digunakan dalam industri otomotif, kimia, elektronika, furniture. Produksi silikon memiliki peluang yang besar untuk dikembangkan, mengingat kebutuhan yang cenderung meningkat.

Proses produksi silikon dari abu ampas tebu dapat dilihat pada Gambar 3. Proses produksi yang direncanakan merupakan pengembangan dari silikon karbida (Suparman 2010) dan silikon semikonduktor (Rohaeti et al. 2010) dari sekam padi dan nanosilika (Setiawan et al. 2015) dari abu ampas tebu.

Rancangan proses produksi silikon dari abu ampas tebu dibutuhkan pelatan produksi. Peralatan yang digunakan berdasarkan dari jenis dan karakterikstik bahan baku yang digunakan. Alat yang digunakan disesuaikan dengan harga peralatan,. Hal ini akan berdampak pada efisiensi dan kelayakan produksi. Adapun jenis dan harga peralatan produksi dapat dilihat pada Tabel 1.

Berdasarkan hasil perhitungan rancangan proses produksi silikon dari abu ampas tebu dibutuhkan peralatan sebanyak 30 unit dengan nilai harga peralatan Rp 30372886 895. Peralatan yang digunakan sudah siap digunakan/pasang.

Proses produksi silikon dari abu ampas tebu, selain membutuhkan peralatan, dibutuhkan tenaga kerja dalam melakukan proses produksi silikon dari abu ampas tebu. Adapun kebutuhan rencana kebutuhan tenaga kerja dapat dilihat pada Tabel 2 dan Tabel 3. 


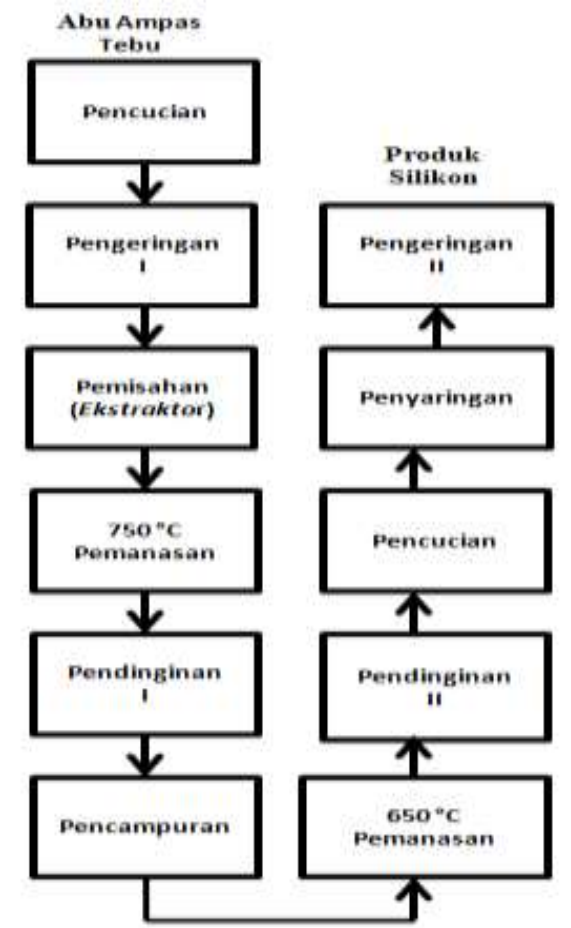

Gambar 3 Proses Produksi Silikon dari Abu Ampas Tebu Pengembangan dari Silikon Karbida (Suparman, 2010) dan Silikon Semikonduktor (Rohaeti et al. 2010) dari Sekam Padi dan Nanosilika (Setiawan et al. 2015) dari abu ampas tebu.

Tabel 1 Jenis peralatan produksi.

\begin{tabular}{clcr}
\hline No & \multicolumn{1}{c}{ Alat } & Unit & Harga (Rp) \\
\hline 1 & Tangki Ekstraktor & 1 & 675922243 \\
\hline 2 & Tangki Pencuci 1 & 1 & 618161708 \\
\hline 3 & Tangki Pencuci 2 & 1 & 419191980 \\
\hline 4 & Tangki HCl & 3 & 19600263328 \\
\hline 5 & Tangki Mg & 1 & 4659494002 \\
\hline 6 & Pompa HCl & 3 & 59100000 \\
\hline 7 & Pompa Filter & 1 & 19700000 \\
\hline 8 & Rotary Dryer & 1 & 150522707 \\
\hline 9 & Rotary Dryer & 1 & 53097464 \\
\hline 10 & Filter & 1 & 150851687 \\
\hline 11 & Furnace 1 & 1 & 115884200 \\
\hline 12 & Furnace 2 & 1 & 247266053 \\
\hline 13 & Cooler 1 & 1 & 168350373 \\
\hline 14 & Cooler 2 & 1 & 247266053 \\
\hline 15 & Mixer & 1 & 271987649 \\
\hline 16 & Screw Conveyor & 1 & 150522707 \\
\hline 17 & Screw Conveyor & 1 & 115884200 \\
\hline 18 & Screw Conveyor & 1 & 525713746 \\
\hline 19 & Belt Conveyor & 1 & 115884200 \\
\hline 20 & Belt Conveyor & 1 & 247266053 \\
\hline 21 & Belt Conveyor & 1 & 271987649 \\
\hline & & &
\end{tabular}




\begin{tabular}{rlcrr}
\hline No & Alat & Unit & \multicolumn{2}{c}{ Harga (Rp) } \\
\hline 22 & Belt Conveyor & 1 & 419191980 \\
\hline 23 & Belt Conveyor & 1 & 150851687 \\
\hline 24 & Belt Conveyor & 1 & 247266053 \\
\hline 25 & Belt Conveyor & 1 & 53097464 \\
\hline 26 & Bucket Elevator & 1 & 618161708 \\
\hline \multicolumn{2}{r}{ Total } & & 30372886895 \\
\hline
\end{tabular}

Sumber: Alibaba.com, 2015.

Tabel 2 Jumlah pekerja.

\begin{tabular}{lccr}
\hline \multicolumn{1}{c}{ Jabatan } & Jumlah & Pendidikan min. & \multicolumn{1}{c}{$\begin{array}{r}\text { Total/bulan, } \\
\text { Rp. }\end{array}$} \\
\hline Direktur & 1 & S-2 & 55000000 \\
\hline Manajer Bagian & 2 & S-1 & 48000000 \\
\hline Sekretaris & 2 & D-3 & 5000000 \\
\hline Kepala Bagian & 6 & S-1 & 39000000 \\
\hline Kepala Seksi & 12 & S-1 & 60000000 \\
\hline Kepala Shift & 20 & S-1 / D-3 & 80000000 \\
\hline Pegawai Staff I & 38 & S-1 / D-3 & 95000000 \\
\hline Pegawai Staff II & 12 & SMA/SMK & 24000000 \\
\hline Operator & 62 & D-3 & 186000000 \\
\hline Satpam & 5 & STM/SMA & 9000000 \\
\hline Supir & 10 & STM/SMA & 15000000 \\
\hline Petugas Kebersihan & 10 & SMA & 13000000 \\
\hline Total & 180 & & 629000000 \\
\hline
\end{tabular}

Tabel 3. Perincian biayas kas.

\begin{tabular}{rlr}
\hline No & \multicolumn{1}{c}{ Jenis Biaya } & Jumlah (Rp) \\
\hline 1 & Gaji Pegawai /tahun & 7548000000 \\
\hline 2 & Administrasi Umum & 754800000 \\
\hline 3 & Biaya Pemasaran & 1132200000 \\
\hline Total & & 9435000000 \\
\hline
\end{tabular}

Tabel 2 menunjukan bahwa tenaga kerja yang dibutuhkan dalam melakukan produksi silikon dari abu ampas tebu dengan kapasitas 10000 ton/tahun sebanyak 180 orang, perekrutan karyawan dilakukan secara bertahap atau disesuaikan berdasarkan kebutuhan produksi. Anggaran yang dibutuhkan dalam pemberih upah tenaga kerja sebanyak 180 orang dalam satu bulan sebesar Rp 629000000.

Pabrik silikon dari abu ampas tebu direncanakan tenaga kerja yang seefisien mungkin. Pendirian pabrik silikon diharapkan dapat memberikan kontribusi dalam menciptakan lapangan pekerjaan. Makin banyak output yang diproduksi dengan tenaga kerja yang lebih sedikit membuat bisnis menjadi lebih baik (Djajadiningrat $e t$ al. 2011).

Berdasarkan Tabel 3 menjelaskan gaji pegawai dalam satu tahun, biaya administrasi umum dan biaya pemasaran. Bagian dari jenis biaya modal kerja produksi silikon dari abu ampas tebu. Modal merupakan faktor input kedua yang menjadi penggerak produktifitas (Djajadiningrat et al. 2011). Produksi silikon dari abu ampas tebu dengan kapasitas 10000 ton/tahun membutuhkan modal dalam melakukan kegiatan produksi. Adapun modal yang dibutuhkan dapat dilihat pada Tabel 4. 
Berdasarkan Tabel 4 bahwa biaya modal kerja terbesar berasal dari bahan baku proses dan utilitas, kemudian piutang dagang, biaya star-up dan biaya kas. Biaya bahan baku proses dan utilisasi merupakan kunci dalam melakukan roduktifitas produksi silikon dari abu ampas tebu. Hal ini dikarenakan nilai jenis biaya hampir dua kli lipat dari biaya lain yang ada didalam jenis biaya modal kerja. Bahan baku berkualitas dihasilkan produk yang berkualitas, sehingga terciptalah produktifitas yang berdampak pada keuntungan perusahaan.

Tabel 4 Jenis biaya modal kerja.

\begin{tabular}{clr}
\hline No & \multicolumn{1}{c}{ Jenis Biaya } & \multicolumn{1}{c}{ Jumlah (Rp) } \\
\hline 1 & Bahan baku proses dan utilitas & 310705377761 \\
\hline 2 & Biaya Kas & 9435000000 \\
\hline 3 & Biaya Start-Up & 26950437723 \\
\hline 4 & Piutang dagang & 187500000000 \\
\hline \multicolumn{2}{l}{ Total Modal Kerja } & 534590815485 \\
\hline
\end{tabular}

\section{KESIMPULAN}

Pemanfaatan abu ampas tebu menjadi silikon merupakan salah satu cara untuk mengurangi dampak dan meningkatkan nilai tambah ekonomis dari abu ampas tebu. Berdasarkan hasil analisis kelayakan produksi silikon dari abu ampas dalam penelitian ini yaitu layak untuk didirikan.

\section{DAFTAR PUSTAKA}

[BPS] Badan Pusat Statistik. 2014. Data Impor Indonesia. Jakarta: Badan Pusat Statistik Jakarta.

[BRI] Perseroan Terbatas Bank BRI. 2015. Suku Bunga Dasar Kredit (Prime lending Rate) PT. Bank Rakyat Indonesia Tbk. http://bri.co.id [1 Maret 2015].

Affandi S, Steyyawan H, Winardi S, Purwanto A, Balgis R. 2009. A Facile Method for Production of HighPurity Silica Xerogels from Bagasse Ash. Journal Advance Powder Technology. 20: 468-472.

Alibaba. 2015. Product Silicon Supply Metal Powder Price. http://www.alibaba.com [25 Maret 2015].

Colin D. 2004. Management and Cost Accounting Sixth Edition. British: British Library.

Djajadiningrat ST, Hendriani Y, Famiola M. 2011. Ekonomi Hijau. Bandung: Rekayasa Sains.

Fardiaz S.1992. Polusi Air dan Udara. Yogyakarta: Kanisius.

Husin A. 2007. Pemanfaatan Limbah untuk Bahan Bangunan. http://www. kimpraswil. go.id [25 Februari 25].

Kalapathy U, Proctor A, Shultz J. 2002. An Improved Method for Production of Silica From Rice Hull Ash. Journal Bio resources Technology. 85: 285-289.

Rohaeti E, Hikmawati, Irzaman. 2010. Production of Semiconductor Materials Silicon from Silica Rice Husk Waste as Alternative Silicon Sources. Journal Material Science and Technology.

Setiawan WK, Indrasti NS, Suprihatin. 2015. Synthesis and Characterization of Nanosilica from Boiler Ash wit Co-Precipitation Method. ICALA. 160-164.

Suparman. 2010. Sintesis Silikon Karbida (SiC) dari Silika Sekam Padi dan Karbon Kayu Dengan Pendekatan Metode Reaksi Fasa Padat. Tesis. Sekolah Pasca Sarjana. Bogor: Institut Pertanian Bogor.

Teixeira RS, Romero M, Rincon MJ. 2010. Crystallization of SiO2-CaO-Na2O Glass Using Sugarcane Bagasse Ash as Silica Source. Journal American Ceramic Society. 93: 450-455.

Timmerhaus KD. Peters MS. 2004. Plant Design and Economics for Chemical Engineer. New York: John Wiley and Sons Inc.

Worathanakul P, Payubnop W, Muangpet A. 2009. Characterization for Post-Treatment Effect of Bagasse Ash for Silica Extraction. Journal World Accad of Science, Energy and Technology. 32: 360-362. 